\title{
Evaluation of E0-1 Hyperion Data for Crop Studies in Part of Indo-Gangatic Plains: A Case Study of Meerut District
}

\author{
Davinder Singh, Rajender Singh \\ Department of Geography, University of Jammu, Jammu, India \\ Email:dsmanhas4@gmail.com,manhasgis@gmail.com
}

Received 5 May 2015; accepted 27 November 2015; published 30 November 2015

Copyright (C) 2015 by authors and Scientific Research Publishing Inc.

This work is licensed under the Creative Commons Attribution International License (CC BY). http://creativecommons.org/licenses/by/4.0/

c) (i) Open Access

\begin{abstract}
Due to the high number of bands in the hyperspectral image, the selection of optimum bands for crop classification is a prerequisite. The Hyperion sensor has 242 spectral bands out of which 143 useable bands were selected. The bands reflected wavelength from 400 to $1000 \mathrm{~nm}$ to the VNIR spectrometer and transmitted the band from 900 to $2500 \mathrm{~nm}$ to the SWIR spectrometer. Spectral Angle Mapping Classification (SAMC) approach and a multi-scale object oriented method are applied for crop studies. The result obtained from the accuracy assessment by comparing Ground Control Points (GCP) with the help of image spectra shows $78 \%$ of overall accuracy. This shows that these data are highly useful in studying the crop diversification.
\end{abstract}

\section{Keywords}

Hyperspectal Remote Sensing, Hyperion Data, Spectral Angle Mapping Classification

\section{Introduction}

Hyperspectral remote sensing or Imaging spectrometry is "the simultaneous acquisition of images in many relatively narrow, contiguous and/or non-contiguous spectral bands throughout the ultraviolet, visible and infrared portions of the electromagnetic spectrum" [1]. Hyperspectral remote sensing is a new technology that is currently being investigated by researchers and scientists with regard to the detection and identification of minerals, terrestrial vegetation and man-made materials and backgrounds. In comparison to multispectral remote sensing which records reflectance from a target in few broad channels, a hyperspectral imaging system acquires information in more than 100 very narrow, defined continuous spectral bands. Radiation from any specified target has been obtained continuously; making it possible to gain detailed information. Furthermore, the success of 
species-level crop classification using broadband satellite imagery is very limited owing to the spectral similarity of various crop species and the finer spectral differences among various crop species, which are not detectable in broadband remote sensing data [2]. Traditionally, agricultural crops are identified using broadband satellite imagery by the classification of satellite images with statistical classifiers such as maximum likelihood classifier [3]. Hyperspectral data can be used in discriminating crop varieties [4]. Hyperion sensor acquires data in push broom mode with a separate detector for each column and each band [5], some of the parameters are robust indicators of the physiological and stress conditions that would potentially affect on crop yield and stress conditions that could potentially affect crop yield thus useful for precision agriculture purposes [6].

\section{Study Area}

Merrut District of Uttar Pradesh State is located between $28.99^{\circ} \mathrm{N}$ Latitude and $77.70^{\circ} \mathrm{E}$ Longitude at an elevation of 219 metres above mean sea level. It is located $56 \mathrm{~km}$ northeast of the national capital New Delhi, and 453 kilometres northwest of the state capital, Lucknow. The study area is an apart of Indo-gangatic plain which is agriculturally highly productive and most of the agriculture area is irrigated. The agriculture is highly productive having mostly irrigated crops and it is the part of Indo-gangatic plains. The major crops during the Rabi season include Sugarcane, wheat and mustard where as the minor crops are identified as Potato, sorghum etc. The district is known for high level of sugarcane production. It covers an area of $2590 \mathrm{sq}$ kms. The present paper is an attempt to study the Potential of Hyperion data for crop identification/classification in Indo-Gangatic plains. However the main focus of this study is on two rabi crops i.e. Wheat and Sugarcane.

\section{Data Used}

Hyperion data image of Meerut District were acquired on 12 March 2005. The data was procured from USGS, USA. Hyperion instrument is to provide high quality calibrated data that support evaluation of Hyperspectral technology from Earth Observing mission. The band reflects from 400 to $900 \mathrm{~nm}$ to the VNIR spectrometer and transmits the band from 900 to $2500 \mathrm{~nm}$ to the SWIR spectrometer. The SWIR overlap with the VNIR from 900 to $1000 \mathrm{~nm}$ allows cross calibration between the two spectrometers. Out of 242 bands 143 bands has been selected for the crop study.

\section{Methodology}

In order to fulfil the objective of the present study the following methodology has been applied, which is shown in the Figure 1.

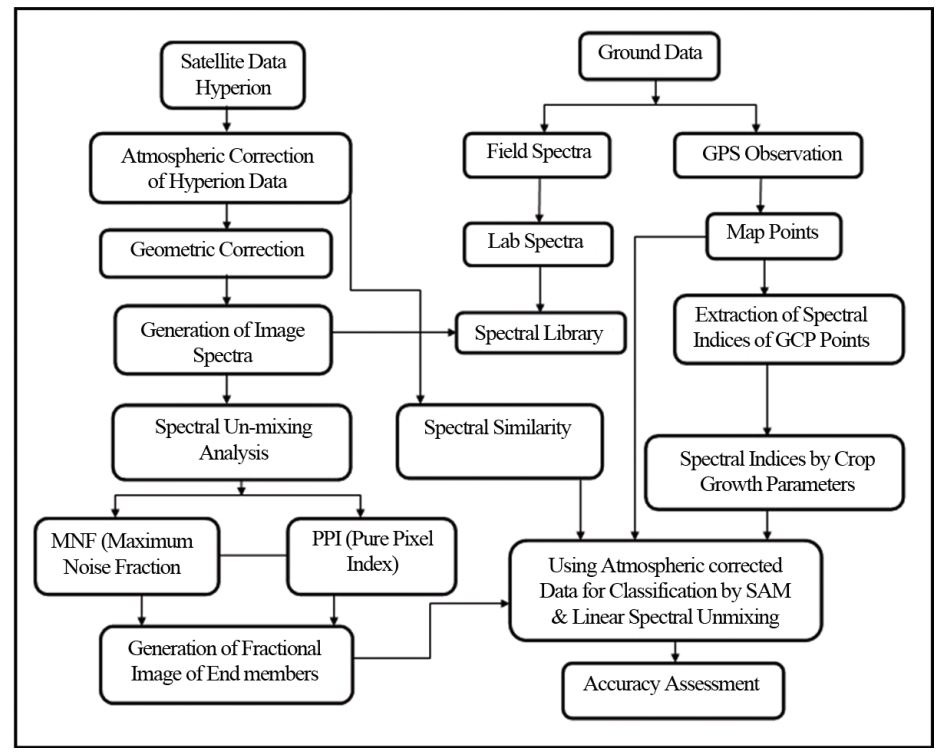

Figure 1. Flow chart of methodology. 


\section{Hyperion Data Processing}

Data processing operations for preparation of the Hyperion data for classification including band selection, correction for bad lines, striping pixels and smile, a pixel based atmospheric correction using FLAASH and a co-alignment were performed as follow. Hyperion data is initially processed by the E0-1 product generation system and distributed in different processing levels. Level L1R is the outcome of the level row products which is subjected to four types of corrections, Dark current effect, Sensor based effect and specific artefacts known as SWIR and VNIR. The radiometric correction applies sensor gain values based on the post launch calibration coefficients.

\section{Bands Selections \& Identification of Bad Columns}

The atmospheric water vapour bands which absorb almost the entire incident and reflected solar radiation and bands that have very severe vertical stripping are usually identified by visual inspection of the image data or atmospheric modelling. The subsets of 143 selected bands are listed in the given Table 1 and Table 2. These selected bands are used for present research.

The high frequency errors in the VNIR or SWIR regions are used to identify the strips in the image bands. In the $1 \mathrm{R}$ products these vertical strips are not corrected. Bands in the high water absorption range from $1400 \mathrm{~nm}$ to $1900 \mathrm{~nm}$ and the bands which had high acceptable noise and streaking were removed from further processing. The method to identify the strips uses the cumulative mean, Variance minimum and maximum of each pixel in each column. The Detection of bad pixel is then replaced with the median value of its neighbourhood. The missing line filter designed in the present study has a local balancing effect on the image (Figure 2).

\section{Atmospheric Correction}

Atmospheric correction of the generated 143 channel Hyperion dataset is performed using Flaash (ENVI Software), an atmospheric correction program based on look-up tables generated with a radioactive transfer code.

Table 1. Location of Bad Columns in level 1R Product.

\begin{tabular}{ccc}
\hline Array & Bands & Wavelength (nm) \\
\hline VNIR & $8-55$ & $426-905$ \\
SWIR & $85-97$ & $993-1114$ \\
& $101-164$ & $1154-1790$ \\
& $187-219$ & $2022-2345$ \\
\hline
\end{tabular}

Table 2. The image spectra improve after performing de-striping and spikes in the VNIR region (300 - $700 \mathrm{~nm}$ ) are reduced and change in the spectra \& seen in SWIR region (2000 - $2500 \mathrm{~nm})$.

\begin{tabular}{cc}
\hline Bands & Bad Columns \\
\hline 8 & $1,6,67,68,114,230,245,246$ \\
9 & $1,6,114,199,230$ \\
11 & $1,6,114,199$ \\
14 & 1,114 \\
56 & $13,16,17,20,32$ \\
78 & $97,245,246,247,256$ \\
94 & 92,256 \\
116 & $1,136,137,256$ \\
119 & $1,239,255,256$ \\
120 & $1,255,256$ \\
\hline
\end{tabular}




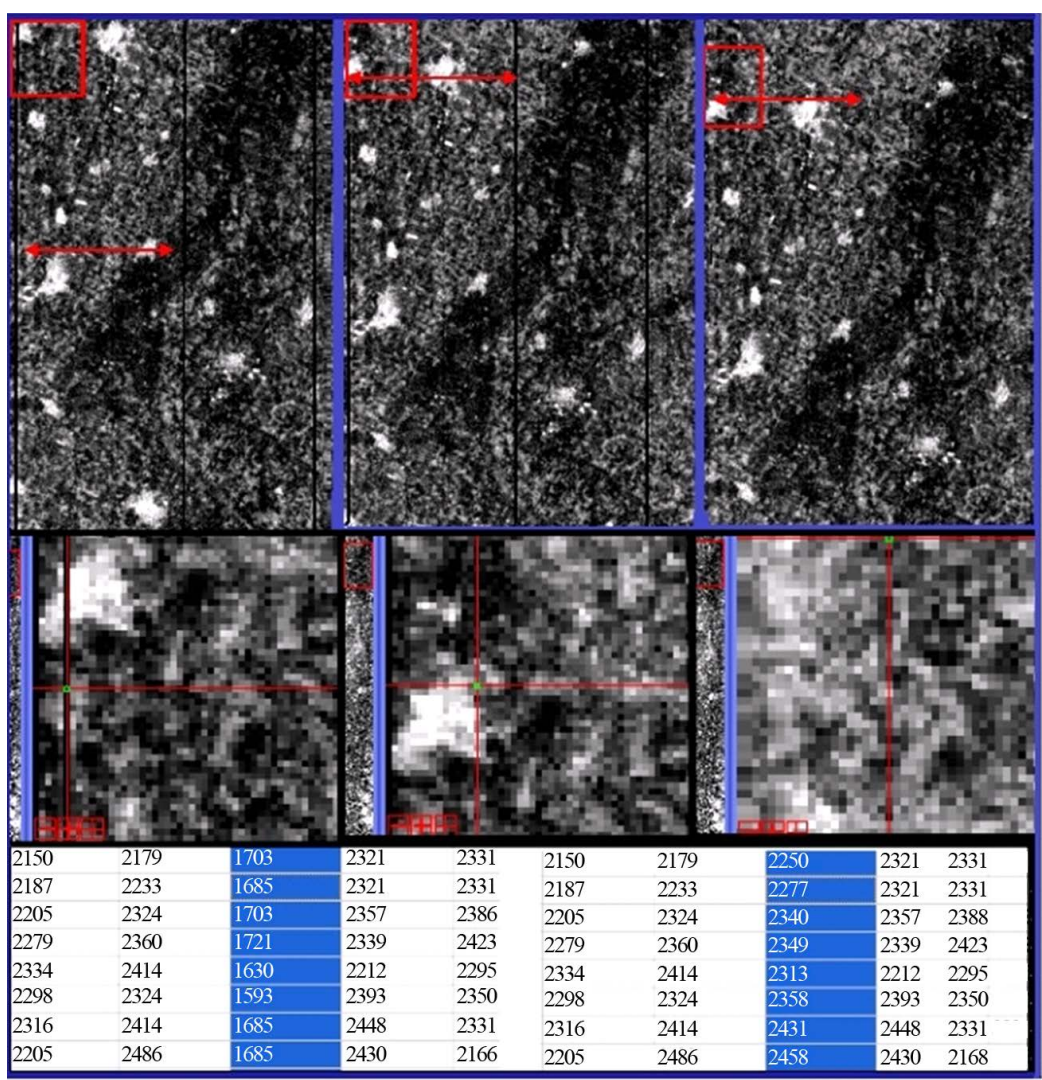

Figure 2. Stripped lines remove by calibrated/spectral smooth method.

As in-flight calibration approach based on two targets in the scene is chosen with in-situ measured spectroradiometric ground-truth data. Atmospheric correction was achieved by using ENVI's Fast line of sight Atmospheric Analysis spectral hyper-cubes (FLAASH). We used the hybrid method of the atmospheric correction to retrieve surface reflectance from Hyperion data.

\section{Pixel Purity Index (PPI)}

The Hyperspectral pure pixels analysis should be separated from the mixed pixels in order to reduce the number of pixels to be analyzed for the identification of the most pure pixels or the End-members. The pixel purity index function finds the most spectrally pure or "extreme" pixel in hyper spectral data. PPI was processed with 10,000 iterations which are always better for the imaging of hyper spectral data. The threshold factor should always be approximately 2 to 3 times the noise level in the data in ENVI Software. The bright pixels in the image (Figure 3) show the spatial location of the spectral End-members.

\section{Spectral Angle Mapper}

The Spectral Angle Mapper Classification (SAM) is an automated method for directly comparing image spectra to known spectra (usually determined in a lab or in the field with a spectrometer) or an end member. This method treats both (the questioned and known) spectra as vectors and calculates the spectral angle between them. This method is insensitive to illumination since the SAM algorithm uses only the vector direction and not the vector length. The result of the SAM classification is an image showing the best match at each pixel. The method is typically used as a first cut for determining the mineralogy and works well in areas of homogeneous regions. The USGS maintains a large spectral library, mostly composed of mineral and soil types, which image spectra, can be directly compared SAM is based on the idea that an observed reflectance spectrum can be considered as a vector in a multidimensional space, where the number of dimension equals the number of spectral bands (Figure 4). 

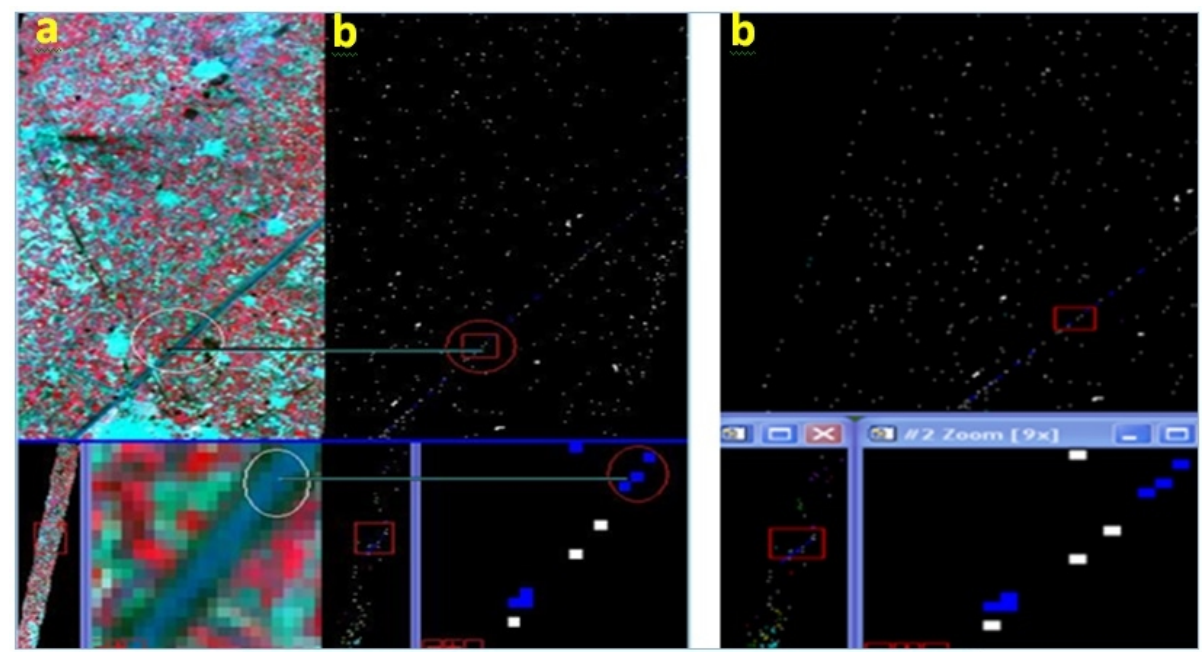

Figure 3. a) Original image; b) PPI Count image.

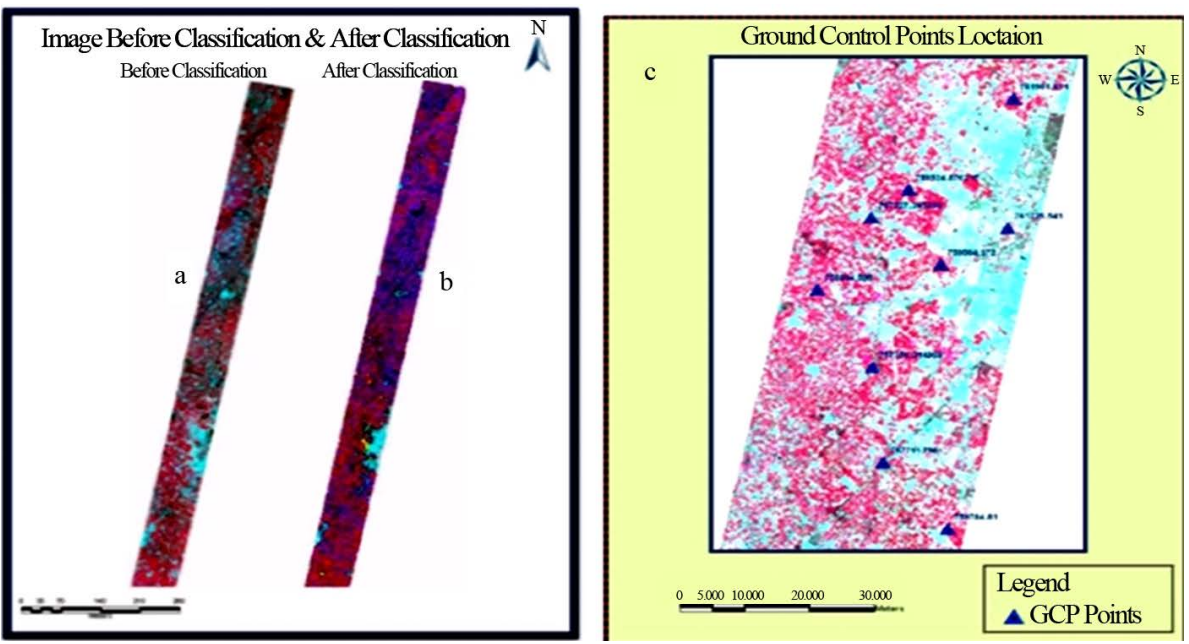

Figure 4. a) Before classification; b) After classification; c) Sample Location (GCP).

It is an automated method for comparing imagery spectra to reference spectra e.g. ASD Ground Spectra. Spectral Angle Mapper Classification in which the input reference is ASD Spectra, to produce rule image of each ASD Spectra \& Produce Classified SAM image based on threshold. Two different materials will have different angles. Smaller angles represent closer matches to the reference spectrum. Pixels further away than the specified maximum angle threshold in radians are not classified. To validate of the image classification 38 GCP points were collected for major classes taken in the present study for the validation of classified image. GPS and classified output was taken to collect points randomly and also to check for the classified areas (Figure 5).

\section{Accuracy Assessment}

The accuracy assessment was performed to quantitatively determine how accurately pixels were classified of different classes (Table 3). The mapping accuracy results is an error matrix (Table 4) that describes an array of numbers indicating how many pixels were classified with each class in terms of the classification and ground truth [7]. The overall accuracy (Kappa Coefficient), producers accuracy, users accuracy (Table 6), error commission and error of Omission (Table 5) as shown in the below tables.

To specify a named variable that contains the commission array \& omission array between the classification image and the ground truth. It is clear from table no 3 and 4 that Hyperion data is quite suitable for the classification as well identification of crops i.e. wheat and sugarcane. The overall accuracy comes to $78.4 \%$, whereas 
Table 3. Ground truth pixel for accuracy assessment.

\begin{tabular}{cccccccc}
\hline \multirow{2}{*}{ Class } & \multicolumn{7}{c}{ Accuracy Assessment } \\
\cline { 2 - 7 } & Settlement & Water & Sugarcane & Wheat & Fallow & Orchard & $\begin{array}{c}\text { Total (Ground truth } \\
\text { pixels) }\end{array}$ \\
\hline Unclassified & 10 & 22 & 2 & 5 & 3 & 4 & 46 \\
Settlement & 39 & 0 & 0 & 0 & 0 & 0 & 39 \\
Water & 0 & 43 & 0 & 0 & 0 & 0 & 43 \\
Sugarcane & 0 & 0 & 40 & 1 & 0 & 1 & 42 \\
Wheat & 0 & 0 & 5 & 48 & 0 & 0 & 53 \\
Fallow & 11 & 0 & 0 & 0 & 62 & 0 & 73 \\
Orchard & 0 & 0 & 1 & 1 & 0 & 15 & 19 \\
Total & 60 & 65 & 50 & 55 & 65 & 20 & 315 \\
\hline
\end{tabular}

Overall Accuracy $=(39+43+42+53+73+19) /(46+39+43+42+53+73+19)=(247 / 315)=78.4 \%$ Kappa Coefficient $=$ 0.7448 .

Table 4. Ground truth pixel for accuracy assessment in percentage.

\begin{tabular}{cccccccc}
\hline \multirow{2}{*}{ Class } & \multicolumn{7}{c}{ Ground Truth Percentage } \\
\cline { 2 - 7 } & Settlement & Water & Sugarcane & Wheat & Fallow & Orchard & Percentage \\
\hline Unclassified & 16.67 & 33.85 & 4 & 9.09 & 4.62 & 20 & 14.6 \\
Settlement & 65 & 0 & 0 & 0 & 0 & 0 & 12.38 \\
Water & 0 & 66.15 & 0 & 0 & 0 & 0 & 13.65 \\
Sugarcane & 0 & 0 & 80 & 1.82 & 0 & 5 & 13.33 \\
Wheat & 0 & 0 & 10 & 87.27 & 0 & 0 & 16.83 \\
Fallow & 18 & 0 & 0 & 0 & 95.38 & 0 & 23.17 \\
Orchard & 0 & 0 & 6 & 1.82 & 0 & 75 & 6.03 \\
Total & 100 & 100 & 100 & 100 & 100 & 100 & 100 \\
\hline
\end{tabular}

Table 5. Error of commission and error of omission in percent and pixels.

\begin{tabular}{ccccc}
\hline Class & $\begin{array}{c}\text { Commission } \\
\text { (Percent) }\end{array}$ & $\begin{array}{c}\text { Omission } \\
\text { (Percent) }\end{array}$ & $\begin{array}{c}\text { Commission } \\
\text { (Pixels) }\end{array}$ & $\begin{array}{c}\text { Omission } \\
\text { (Pixels) }\end{array}$ \\
\hline Settlement & 0.00 & 35.00 & $0 / 39$ & $21 / 60$ \\
Water & 0.00 & 33.85 & $0 / 43$ & $22 / 65$ \\
Sugarcane & 4.76 & 20.00 & $2 / 42$ & $10 / 50$ \\
Wheat & 9.43 & 12.73 & $5 / 53$ & $7 / 55$ \\
Fallow & 15.07 & 4.62 & $11 / 73$ & $3 / 65$ \\
Orchard & 21.05 & 25.00 & $4 / 19$ & $5 / 20$ \\
\hline
\end{tabular}

Table 6. Producer accuracy and user accuracy percent and pixels.

\begin{tabular}{ccccc}
\hline Class & Producer Accu. (Percent) & User Accu. (Percent) & $\begin{array}{c}\text { Producer Accu. } \\
\text { (Pixels) }\end{array}$ & $\begin{array}{c}\text { User Accu. } \\
\text { (Pixels) }\end{array}$ \\
\hline Settlement & 0.00 & 35.00 & $0 / 39$ & $21 / 60$ \\
Water & 0.00 & 33.85 & $0 / 43$ & $22 / 65$ \\
Sugarcane & 4.76 & 20.00 & $2 / 42$ & $10 / 50$ \\
Wheat & 9.43 & 12.73 & $5 / 53$ & $7 / 55$ \\
Fallow & 15.07 & 4.62 & $11 / 73$ & $3 / 65$ \\
Orchard & 21.05 & 25.00 & $4 / 19$ & $5 / 20$ \\
\hline
\end{tabular}



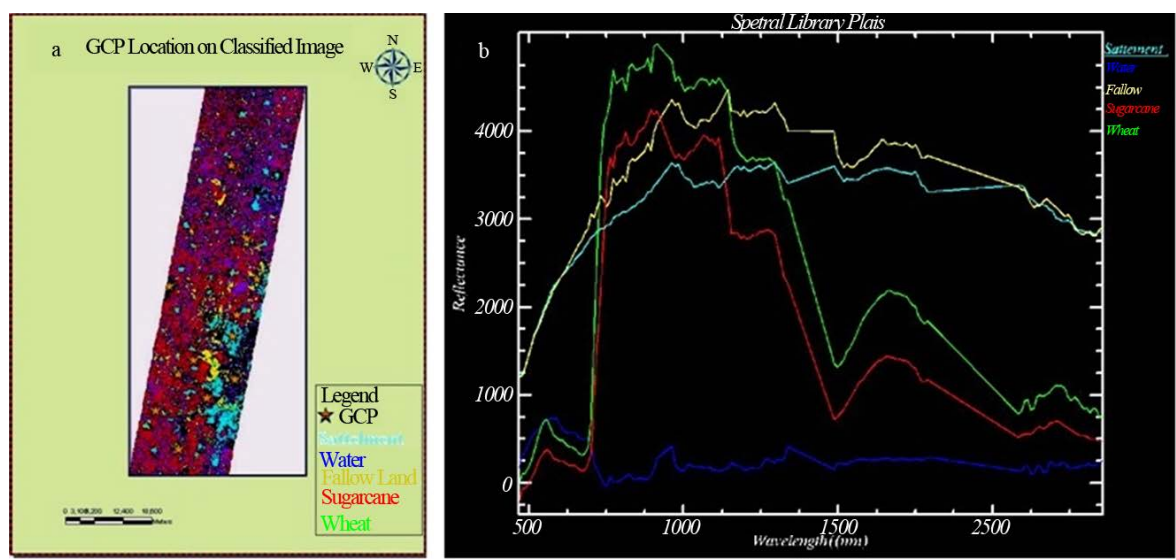

Figure 5. a) Classified image with GCP; b) Spectral signature of the image.

the percentage of accuracy for sugarcane and wheat is above eighty percent.

\section{Conclusion}

Hyperion had 242 bands covered the visible, near infrared bands (400 - $2500 \mathrm{~nm}$ ) with $10 \mathrm{~nm}$ bandwidths. Typically 143 bands were provided in calibrated data. The selection of the Bands from the raw data format L1R is only 143 bands in which we find out the results of the Spectral Angle Classification and its Accuracy Assessment. The result of the SAM Classification comes, in which the Overall Accuracy is 78\% and Kappa Coefficient value is 0.7448 . Spectral angle mapping classification can be used to do best match with object by calculating spectral angle to estimate the similarities between spectrums. The endmemeber projection vector can be distinguished objects and its background regardless of the distribution of the object information. The outcome of the study shows that these data can be successfully used for crop identification.

\section{References}

[1] Jensen, J.R. (2005) Introductory Digital Image Processing. 3rd Edition, Prentice Hall, Upper Saddle River.

[2] Broge, N.H. and Leblanc, E. (2000) Comparing Prediction Power and Stability of Broadband and Hyperspectral Vegetation Indices for Estimation of Green Leaf Area Index and Canopy Chlorophyll Density. Remote Sensing of Environment, 76, 156-172. http://dx.doi.org/10.1016/S0034-4257(00)00197-8

[3] Philipp, I. and Rath, T. (2002) Improving Plant Discrimination in Image Processing by Use of Different Colour Space Transformations. Computers and Electronics in Agriculture, 35, 1-15. http://dx.doi.org/10.1016/S0168-1699(02)00050-9

[4] Galvao, L.S., Formaggio, A.R. and Tisot, D.A. (2005) Discrimination of Sugarcane Varieties in Southeastern Brazil with EO-1 Hyperion Data. Remote Sensing of Environment, 95, 523-534. http://dx.doi.org/10.1016/j.rse.2004.11.012

[5] Goodenough, D.G., Dyk, A., Niemann, K.O., Pearlman, J.S., Chen, H., Han, T., Murdoch, M. and West, C. (2003) Processing Hyperion and ALI for Forest Classification. IEEE Transactions on Geoscience and Remote Sensing, 41, 1321-1331. http://dx.doi.org/10.1109/TGRS.2003.813214

[6] Zarco-Tejada, P.J., Ustin, S.L. and Whiting, M.L. (2005) Temporal and Spatial Relationship between within Field Yield Variability in Cotton and High Spatial Hyperspectral Remote Sensing Imagery. Agronomy Journal, 97, 641-652. http://dx.doi.org/10.2134/agronj2003.0257

[7] Janssen, L.L.F. and vander Wel, F.J.M. (1994) Accuracy Assessment of Satellite Derived Land-Cover Data: A Review. Photogrammetric Engineering and Remote Sensing, 60, 419-426. 